\title{
Reading with Abby: A case study of individual tutoring with a young adult with Down syndrome
}

\author{
Kelly M. Gallaher, Christina E. van Kraayenoord, Anne Jobling \\ and Karen B. Moni \\ Schonell Special Education Research Centre, The University of Queensland, Australia
}

\begin{abstract}
This case study examined the impact of a series of tutoring sessions on the literacy development of a young woman with Down syndrome. The sessions were conducted within the LATCH-ON (Literacy and Technology-Hands On) program at the Schonell Special Education Centre at the University of Queensland and made use of technology resources in addition to other methods of instruction. The first author assumed the role of participant observer through the reported sessions and acted as an individual tutor to the young woman. Data obtained from an initial screening indicated that the young woman had only limited word decoding strategies when reading text, and consequently, had significant problems with comprehension. Instruction during individual tutoring sessions focused primarily on phonics instruction, as well as other decoding strategies, such as sight word recognition. Specific instructional strategies employed by the first author are discussed. Within the context of the LATCH-ON program, the impact of individual instruction on the development of literacy is examined and discussed.
\end{abstract}

Keywords: Reading, literacy, Down syndrome, intellectual disabilities, tutoring, case study

\section{Introduction}

Historically, beliefs about the potential of individuals with intellectual disability have been characterised by low expectations of academic success (Farrell \& Elkins, 1991), limited services (Bochner \& Pieterse, 1996), and restricted access to opportunities for instruction (Fowler, Doherty \& Boynton, 1995). In the last two decades, however, substantial changes in literacy education have created a context in which students with intellectual disabilities are better supported in their language and learning. Consequently, they could be more likely to achieve social and academic success. This is especially true for students with Down syndrome, who have benefited from "better medical treatment, earlier and more professional language intervention, and greater access to systematic reading instruction in and out of school" (Fowler et al., 1995, p. 182).

In terms of literacy instruction, however, there appears to be a significant discrepancy between the opportunities for young children with Down syndrome and those available in their later years. Literacy instruction is often provided to children with Down syndrome in the initial years of primary school, but is gradually withdrawn at about the fifth grade, when it appears educators assume a learning plateau has been reached (Farrell \& Elkins, 1991). From that point on, there is a shift in emphasis from literacy acquisition to more practical instruction in life skills.

This shift in educational objectives is especially limiting to students with Down syndrome, as "studies have indicated that due to slowness in development, it likely that the young person with Down syndrome is ready to benefit from formal education at about the time that it is no longer routinely available" (Tingey, 1988, p. 19). Primarily, instructional emphasis is placed on life skills and vocational training to the exclusion of literacy education at a time when developmentally students with intellectual disabilities may benefit most from such a focus. As a result, there is little data about literacy achievement among adolescents and adults with intellectual disabilities, and there is an absence of research related to establishing effective instructional approaches (Farrell \& Elkins, 1991; van Kraayenoord, 1992).

A synthesis of findings in literature related to the reading abilities of students with intellectual disabilities reveals that a great deal of the available data concentrates on children (e.g., Buckley, 1985; Buckley \& Bird, 1993; Cossu, Rossini, \& Marshall, 1993; Jenkinson, 1992; Kabrich \& McCutchen, 1996; Kemp, 1996; Koppenhaver, Spadorcia, \& Harrison, 1998; Wolman, van den Broek, \& Lorch, 
1997) rather than on adolescents and adults (e.g., Fowler et al., 1995). Available research indicates that students with intellectual disabilities often have difficulties with the acquisition and application of word decoding strategies (Jenkinson, 1992), but that appropriate teaching may allow these students to acquire decoding skills (Fowler et al., 1995). Studies including those cited above, also revealed that students with intellectual disabilities are able to discriminate letters, blend sounds, associate individual letters and consonant blends to sounds, recognise whole word patterns but generally had slower reading speeds. With respect to comprehension, students with intellectual disability had significant difficulties in this aspect of reading and recalled less than non-disabled students.

Drawing implications from available research is especially difficult, as the conclusions reached are cautious and/or call for further research (e.g., Conners, 1992; Cossu et al., 1993; Fowler et al., 1995; Kabrich \& McCutchen, 1996; Koppenhaver et al., 1998).

The limited conclusions concerning the literacy development of students with intellectual disability have significant implications for the expectations of literacy achievement among these individuals, and the design of instructional approaches. If literacy development does follow the same pattern as emergent literacy theory suggests, then instructional designs should follow accordingly. However, if students with intellectual disabilities do not progress through similar stages as their non-disabled peers, then special adaptations in instructional design should be made in order to ensure effective instruction. This is particularly relevant to the application of computer technology in the context of instruction. The lack of conclusive findings with regard to literacy instruction for individuals with intellectual disabilities, including the use of computers, suggests a need for research in this area.

The purpose of this case study was to document and evaluate some of the strategies implemented during a series of individual tutoring sessions with a young adult with Down syndrome. The sessions focused specifically upon the effects of particular strategies and instructional methods in the development of the student's literacy skills, including phonological awareness, sight vocabulary, and phonic skills. These skills have been cited as essential to the development of reading comprehension and the production of meaningful writing (Adams, 1990). The case study examined the use of computer-based learning activities which were integrated into the teaching and learning activities.

The case study was undertaken within the LATCH-ON research and teaching program coordinated by a research team at the Fred and Eleanor Schonell Special Education Research Centre in the School of Education, The University of Queensland. The program is directly associated with the Schonell Centre's Down Syndrome Research Program, which was established in 1977. A detailed description of the LATCH-ON program, its design and implementation, is provided by the principal investigators Moni and Jobling (2000). The students who participated in the program ranged in age from 18 to 21 years, with five young women and three young men enrolled. The reading levels of the students ranged from emergent literacy to approximately Year 7 in decoding skills, with a lower level of ability in comprehension skills.

Special features of the program include small-group and individual instruction, and access to computer technology, including literacy software and the Internet. Computerbased learning is linked with other approaches to literacy instruction in order to provide a comprehensive range of instructional strategies and learning opportunities for the students. A program director, with extensive knowledge and experience in the area of literacy instruction and research, is primarily responsible for the instructional planning and implementation. Primary aims of the program include the development of literacy skills and the use of computer technology to enhance literacy, as well as the enhancement of self-concept and life opportunities through the expected outcomes of this literacy learning. The case study reported here was undertaken with one of the young women who participated in the program during the first year.

\section{Method}

\section{The participant: Abby}

Abby (a pseudonym) was a 19-year-old young woman with Down syndrome who lived with her parents and had two older sisters. She travelled to the program by taxi. She had completed 12 years of special education, and her reading ability was assessed as having the characteristics of an emergent reader. Abby's enrolment in the program seemed "like a natural progression" from her schooling, according to her mother. In addition to the LATCH-ON program, Abby participated in a work experience program, was involved in sport as a member of a bowling team, and attended karate classes regularly. Abby enjoyed sport, and was particularly interested in basketball, baseball, and swimming, in addition to watching movies and listening to music. Abby's participation in LATCH-ON included formal informed consent from her parent to participate in studies being conducted as part of LATCH-ON as long as her name and identity were protected.

\section{Assessments}

Abby was assessed using specific measures at the beginning of the program, in order to establish a baseline level of performance for the development of the teaching program.

The research team conducted a series of observations which were aimed at determining Abby's strengths and weaknesses in different aspects of literacy. These were drawn from a range of tests and activities in which she participated during the assessment session. The tests used were the Neale Analysis of Reading-Revised and the Neale Diagnostic Tutor, a section of the Neale Analysis of Reading-Revised (Neale, 1989), and the Woodcock Reading Mastery Tests (Woodcock \& Johnson, 1989). The assessment measures and activities also included a discussion of 
Abby's portfolio (a collection of awards and recognitions she had received while in school), her account of photos she had brought with her, a reading from a favourite and familiar book, and a short piece of writing that she completed during the screening.

\section{Reading}

From these assessments, the research team determined that Abby could identify a favourite and familiar book and was able to "read" from this book. She understood the principle of directionality and knew how to read books (left to right, top to bottom). She understood how texts were organised to tell a story. An understanding of basic story grammar and identification of characters, heroes and villains, the plot, and the climax of a story were skills she also had. Abby was able to give a detailed recount of a story from memory and showed an understanding that pictures can be used as cues to finding words in a story. She showed good concentration, was motivated to read, and enjoyed the shared reading activity.

Despite these strengths, Abby was not able to sound out letter combinations and had difficulty decoding words. Instead, when she attempted to read, she guessed at the words and substituted any word she knew for the text. Consequently, she did not comprehend the text she was reading. She demonstrated a need for phonics instruction, as well as other decoding strategies, such as sight word recognition.

\section{Writing}

Abby was confident about writing and was happy to write. She understood the purpose of writing and could form letters correctly. However, her writing skills were emergent, requiring considerable support to make progress. While she understood how to form letters, she did not yet have the skills to understand the relationships letters have to sounds and meaning. Abby had a limited understanding of the concept of words and how these are put together to form sentences.

Ultimately, the research team had ascertained that Abby's performance on assessment measures indicated that she needed further instruction in phonological skills, sight word recognition, concepts of print such as words and sentences, and writing strategies. These demonstrated needs guided the instructional design in the LATCH-ON program and the tutoring sessions described in this case study.

\section{Procedure}

A case study approach was used for this investigation. This approach allowed the dynamic contexts of the participant and activities to be captured. The qualitative nature of the case study data collection and analysis also enabled a detailed and descriptive account of the tutoring program's development and of the participant's literacy experiences.

This case study was characterised initially by participant observation which took place from March to July, during the two days of the program each week. The first author's participation in the LATCH-ON classroom as an instructional aide, enabled Abby to become accustomed to her role in the classroom context. This provided a more naturalistic situation for first author observations, as the student did not feel she had to act differently in her presence.

The first 6 weeks of participant observation involved a moderate level of involvement, with observations of class sessions and participation in activities for approximately 2 to 3 hours during the morning session. During this period, particular attention was directed towards becoming more familiar with the dynamics of the group and learning about the structure of the LATCH-ON program. Beginning in May and continuing to the end of July, the first author began to provide more individualised support to assist Abby to focus her work during group sessions. In August and September a series of 12 individual tutorials were conducted. These form the basis for the data presented in this article. A variety of instructional strategies were introduced and utilised during these sessions, with instruction which focused upon meeting the needs she demonstrated in her initial assessment screening.

\section{Data collection/analysis}

The participant sessions and interactions in selected activities were documented in field notes immediately after each session. These notes were then reviewed for significant themes or patterns which might emerge concerning Abby's literacy development. As the notes were fairly general and subjective in nature, more detailed techniques such as time and event sampling, and checklist formats were added.

\section{Video/audio recordings}

Video recordings were made by the research team of all students during group instruction sessions once or twice a month. These recordings were accessed by the first author and were used to verify the field notes. A total of 5 one-hour videos were used to supplement the field notes. In addition, the first author made video and audio tape recordings during the individual tutoring sessions with Abby. Of the 12 tutoring sessions conducted, 11 were recorded either on audio $(\mathrm{n}=9)$ or video $(\mathrm{n}=8)$ tape (occasionally, both audio and video tapes for the same session). These recordings were later transcribed according to Silverman's (1993) guidelines, and analysed for evidence of literacy behaviours. Throughout the data analysis process, categories and themes that appeared over time and across sessions were noted and documented. Specifically, Abby's interactions with text, and her approaches to writing were a focus.

\section{Interviews}

Interviews were undertaken with Abby, the program director, and Abby's mother to further supplement other data. The main focus of these interviews was Abby's attitudes and evaluation of her progress in the program. The program director and Abby's mother provided additional data on these topics. Themes that appeared consistently across the interview sessions were noted and these were used as further evidence for Abby's progress. 


\section{Student artefacts}

Student-produced artefacts, such as writing samples, were collected and evaluated as an additional means of documenting the development of Abby's literacy skills. The samples were evaluated for representation of initial consonants and other phonemes in words, the separation of words into discrete strings of letters, and length of composition. This evaluation was particularly helpful for establishing her approach to writing tasks.

\section{Results}

The following section is a discussion of the literacy development that occurred as a result of Abby's participation in the tutoring sessions. It should be noted that these sessions ran concurrently with LATCH-ON group instruction and strategies were designed to maintain congruency between whole group and individual teaching approaches. Specific attention is given to Abby's reading and writing achievements, her interactions with text, and approaches to writing. Changes in her self-confidence and attitudes toward literacy are also noted.

\section{Reading and writing achievements}

From the very beginning of the program, both the program director and the first author worked with Abby on phonological skills. The specific context of instruction varied with each task, but most often resembled providing Abby with a sound for which she had to supply a letter. Very often, this occurred while Abby was writing, or copying words from the board at the front of the classroom. Rather than having her look back and forth between the board and the paper, the first author asked her to identify the initial consonant in a word she wanted to write down and then repeat the word, with emphasis on the beginning sound. Once she identified the correct letter, the researcher would continue to the next sound, breaking the work into its individual phonemes. Through this practice, it was expected that Abby's phonological skills would develop and her awareness of the phonemes in words would increase.

Initially, Abby's strategy for identifying initial consonants and individual phonemes was purely random guesswork. While guessing may be considered a legitimate word decoding strategy, it is most often practised after specific information has been determined, making it an "educated guess" rather than a "random guess." She would indiscriminately guess the letters she wrote down, and consistently demonstrated this random guessing strategy when completing a phonics tutorial (Phonics Alive!, 1996) program on the computer during individual instruction, as she had discovered that this strategy eventually yielded a correct response, and consequent positive feedback. This is evident from observations made by the LATCH-ON program director and the first author, as well as in the software program's error records. The pattern of random guessing did not appropriately reflect Abby's demonstrated ability to identify most letter sounds in initial assessments, but she seemed to have learned that guessing was a useful strategy.
Abby was highly motivated to use the computer for any task and the typing tutorial gave her an opportunity to rehearse her letter identification skills but she needed significantly more practice. Abby frequently used a word-processing program. The use of this program facilitated her manipulation of text and enlarging the text made it easier for her to read. However, the process of transferring her text from a piece of paper to the computer screen did not seem to increase Abby's use of phonological skills over this period of time, nor did it reinforce sight words, or writing strategies which had been developed. Also the use of the Internet was motivating and gave Abby a meaningful purpose for reading.

In an effort to counter Abby's ineffective strategy of indiscriminate guessing, the first author modelled more valid alternatives, such as listening to the phonemes in words spoken by others, and repeating words aloud while recording corresponding letters of the alphabet. Eventually, Abby refrained from guessing indiscriminately and took the time to consider what sounds she heard at the beginnings of words. She started to begin a word with the correct letter, and even included other letters in a word which represented appropriate combinations of sounds, for example ' $b$ ' and 'ask' in the word 'basketball'. When the first author continued to model a "sound it out" strategy, Abby interrupted by saying, "I know, I know." In addition, Abby's practice of guessing became an effective strategy, as she attended to the initial letter in a word and used this information to guide her guess. The use of this technique was evidenced when she occasionally read an unfamiliar word as a word with the same initial consonant.

Over the course of the tutoring program, Abby learned nine new sight words, which came directly from words she was attempting to spell in her own writing. These words were at, am, see, book, my, very, read, is, and her own middle name. As most of the intensive sight word instruction occurred during the individual tutoring sessions, Abby's sight word recognition for these new words effectively occurred over 12 sessions, which is comparable to Lalli and Browder's (1993) findings.

While Abby had a strong foundation of knowledge concerning the concepts of print, she did not understand the difference between a word and a sentence. Explicit instruction in these concepts, in conjunction with consistent opportunities for reading and writing, helped Abby to gain a clearer understanding of words, word boundaries, and sentences.

By the end of the tutoring program, Abby could identify the difference between a word and a sentence, and understood that sentences were made up of words. In fact, this understanding was most dramatically demonstrated by her diary entries, shown in Figure 1. At the end of each day, the students were asked to write down independently some daily activities in their diaries. Initially, Abby's entries contained strings of letters with no boundaries; later, her words became represented by discrete boundaries, and the formation of sentences is occasionally evident. 


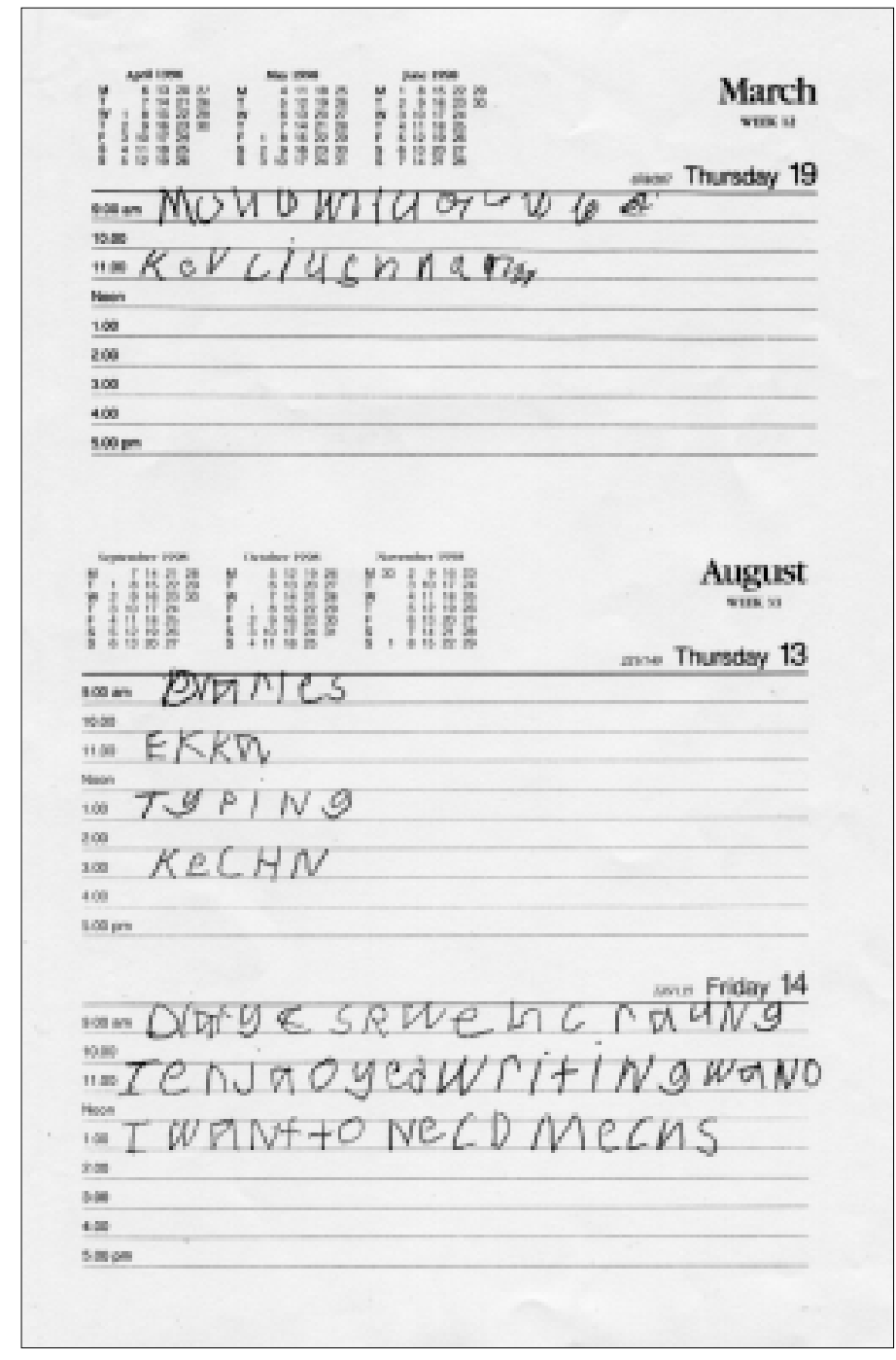

Figure I. Abby's diary entries for March 19 and August I3-14

\section{Interactions with text and approaches to writing}

Initially, Abby's random guessing strategy was also extended to any reading or writing task. In a reading task, for example, Abby would indiscriminately substitute words within a text which had no relation to one another or to the actual text itself, which demonstrated that she had no comprehension of what she read. In accordance with modelling strategies (used in direct instruction approaches), the first author frequently encouraged Abby to pause before she read a particular word and check the initial consonant or whole word representation to assist her in decoding. When she read sentences with which she was familiar in her book, and came to a word she could not remember, she was encouraged to skip the word and come back to it once she had read the rest of the sentence.

\section{Excerpt from Transcript 8: 3 September}

A: I am a very guh:

$R:$ what does it start with?=

$A: \quad=$ very

$R:$ what does it start with?=

$A: \quad=f=$

$R:=m m-h m m$. what sound?

A: $f$

$R:$ what sound? what does an $f$ say?

A: $/ f /$

R: I am a very /f/

A: very. I am a [very good girl.

$R:[$ very $\quad m m m . / f / / a / / s / / t /$

A: sat.

$R: \mid f / / a / / s / / t /$. Skip that word, go to the next one. ((A points to "runner"))

A: run $=$

$R:=$ run. I am a very

A: fast runner $=$

$R:=$ Beautiful. If you don't know the words sometimes, you can skip down to the next one and figure it out.

In a writing task, when independently composing an idea, Abby would first decide how the idea should be organised, often stating aloud what she was going to write. She would then guess a string of letters indiscriminately, with no correspondence to the words she had previously spoken. Consequently, her writing was comprised of strings of random letters, often without discrete word boundaries. To correct this ineffective strategy, the first author encouraged Abby to say aloud the words she was preparing to write, so that she would be better able to supply appropriate letter representations of the phonemes in the words.

\section{Excerpt from Transcript 3: 13 August}

A: getting $=$

$R:$ getting. what do you hear? you write down what you hear. Ge:tting. Ge:tting. Say it out loud if you need to.

A: ((whispers)) getting ((writes down "GT”))

When she employed this strategy, Abby was more likely to begin a word with the correct letter. In the initial sentence writing sessions, Abby supplied a correct initial consonant for one or two words in the sentences she wrote, which typically consisted of six or seven words in total. By the end of the tutoring session period, Abby was supplying correct initial consonants for the majority of words in her sentence, and in the last session, in every word of her sentence.

As she approached a reading or writing task, Abby also demonstrated a consistently high motivation level for reading and writing activities that involved the use of the computer. When invited in class sessions to choose an 
activity to complete, Abby invariably suggested a computer related activity. Usually, she demonstrated a desire to look up information on the Internet, or to type a draft of something she had written using a word-processing program. When using Internet services, Abby frequently relied on pictures and icons to guide her progress through web pages and links and remained highly motivated throughout the year in these activities.

\section{Self-confidence and attitudes toward literacy}

In both reading and writing activities, Abby demonstrated an increased confidence in her ability, and consequently, an increasing independence in the classroom. Initially, when composing texts in the tutorial sessions, Abby would rely upon the first author to come up with suggestions and ideas for sentences. When she did arrive at her own ideas, she would say them aloud and wait for approval, or correct spelling, before writing them down. Ultimately, she became a more independent writer, often jotting down a couple of words during class discussion, or composing sentences without waiting for approval or further instruction. During an activity where the students were asked to compose a "Hero Fax" to their favourite athlete at the Commonwealth Games, the coordinator began the activity with a class discussion. During the discussion, Abby was busy writing:

\section{Excerpt from event sampling record: 17 September}

A: ((to herself $))$ I know who I want to write down. Kieran. Kieran. ((writes "Kecle")) Perkins ((writes "Pechi)). See, look ((addressing K)) See, look. Kieran Perkins.

It is also interesting to note that interviews with Abby produced consistently high confidence in reading, writing, and computer use. She demonstrated positive attitudes toward the program at every stage, including positive evaluations of her own progress. Information concerning Abby's increase in confidence was corroborated by interviews with both the program director and her mother, conducted at different stages. The program director cited a decrease in tears and increased class participation as evidence for Abby's increased confidence during an interview midway through the program. Abby's mother also noticed a significant change in Abby's behaviour, reporting that Abby was much more confident, more focused, and her attention span was longer.

Within the tutoring sessions a number of factors may have contributed to these results. Teaching strategies and activities that were meaningful to Abby and grounded in her strengths and interests as well as her growing confidence in herself as a reader and writer were considered of particular relevance. Some noted effective instructional strategies were:

\section{Predictable books and repeated readings}

As a consistent part of the tutoring sessions, Abby read from a set of predictable books. The books utilised in these sessions were constructed with repetitive sentence structures or rhyming patterns that allowed Abby to predict how the sentence would be read. Abby's ability to anticipate patterns in the sentences came from her everyday use of language and the skills she employed when listening to people speak. Each book was read more than three times, which allowed Abby to become familiar with the structure and content of each story. The predictability of the books used and the repeated readings of those books served two main purposes.

First, because Abby could anticipate the patterns presented in the books, she could read an entire book with little or no assistance, which was a new accomplishment for her. As a more confident reader, she enjoyed the success she experienced and became enthusiastic about reading books she had seen before. Eager to demonstrate her ability, she read the books to the program director. With each reading, she developed increased fluency and made fewer errors. As Abby often pointed to the words as she read, each time she read a particular book she was more successful with a print-to-speech match. Thus, her phonological skills also developed through the use of these materials.

Second, with each re-reading, Abby became more aware of the text she was encountering, and paid more attention to the words themselves. On more than one occasion, she corrected herself after substituting or inserting a word that might have made sense in a sentence (that is, a semantic error), but that was not the actual word. This suggested that she began to attend to the words themselves, particularly the initial consonants.

\section{Sentence writing}

One of the major components of the individual tutoring sessions was the joint construction of sentences for Abby's "book." After she composed the sentence and read it aloud, the first author printed a typed version of the sentence for use during the next session. Once she read the typed sentence, it was cut apart into individual words, and it was Abby's task to rearrange the words into the original sentence. She then glued the words in order (including punctuation - usually a full stop at the end of the sentence) into her book, and read the reconstructed sentence. Rereading sentences from previous sessions were also part of this session.

This particular strategy served a number of purposes. It gave Abby a very meaningful purpose for writing and it provided a means of explicitly discussing and learning the concepts of words and sentences. It was an additional means of practicing phonemic awareness in writing, it provided Abby with an opportunity to read a familiar text (ones that she had personally composed) and it provided a basis from which sight word instruction could be formed. 


\section{Sight word memory}

A sight word memory game became highly motivating for Abby and was therefore included in every tutoring session. Twenty-two index cards printed with 11 sight words twice over, were turned face down on a table. Instead of taking the list of words from a standardised graded sight word list, the words were taken directly from Abby's writing. While some familiar words, such as the, cat, and Abby's name were included in the deck, new words, such as very, read, and book were also included. This ensured that Abby would experience some success with words she knew, while she might initially be challenged by the words she did not know. The object of the game was to turn over two cards to get a match. In order for "the match" to win a point, the player had to be able to read the words on the card. Once all the words had been matched, the player with the highest number of matches was declared the winner. This game provided her with an opportunity to revise words used in writing and to apply her knowledge in a different context.

\section{Discussion}

This case study was conducted within the LATCH-ON program, an ongoing program of teaching and investigating the literacy development of young adults with Down syndrome. While Abby was certainly not representative of all young adults with Down syndrome in the program, she demonstrated many of the same characteristics that had been documented in research examining the literacy skills of individuals with intellectual disability. She frequently attended to the initial letter when identifying a word and would substitute the rest of the word (e.g., run for read). Similarly, she had difficulties with the acquisition and application of word decoding strategies, such as applying knowledge of regular spelling patterns to unknown words. It was this difficulty that prompted the extensive phonics instruction in the tutoring sessions. The phonemic errors that Abby made were also often semantic errors, which were evidence that she was translating print to meaning, rather than from print to speech. These errors were apparent during the reading of predictable books. However, as Abby became more fluent with each reading, she corrected these semantic errors.

Abby was able to discriminate letters, blend sounds, and associate vowels or consonant letters to sounds. She was able to recognise whole word patterns, as demonstrated by her ability to recognise sight words. In addition, during a phonological skill activity, Abby demonstrated an ability to recall words that were phonemically similar which utilised the endings (rhymes) of $a t$ and $a n$.

Abby's written expression skills were still considered emergent at the end of the research period, although she was able to form her letters with reasonable ease and degree of clarity. Her use of phonemic principles in writing was a necessary focus of instruction and, as a result, she was more likely to use correct initial consonants in her writing.
This case study suggested that Abby's literacy development was characterised by qualities that were similar as well as qualities that were different to those of emergent literacy stages of non-disabled students. Abby developed the ability to associate consonant and vowel sounds with letter representations and to recognise whole word patterns, in a similar fashion to non-disabled emergent readers. However, she continued to have difficulties with the application of word decoding strategies, and produced semantic errors which are characteristics typical of students with intellectual disabilities. Consequently, from the findings of this case study, it can be concluded that Abby's literacy development was not entirely characteristic of a non-disabled emergent reader, although some similarities did exist.

From the field notes of the case study, anecdotal evidence suggested that there were no particular benefits for Abby in the use of technology, and this finding would be counter to the conclusions reached by Marston, Deno, Kim, Diment and Rogers (1995), concerning the efficacy of computerbased instruction. However, she did show a great deal of interest in activities that involved the use of the computer which may have been associated with Abby's motivation. More formalised records on the use of technology within the various classroom settings at LATCH-ON, kept over a longer time period, may allow benefits to be ascertained for certain strategies which promote learning to read. Also, computer instruction may be beneficial for students at higher levels of reading ability than was examined in this case study.

The application of findings of any case study to general populations is often questioned as a consequence of the singular nature of this research approach. Still, the case study approach is clearly valuable as an in-depth exploration of a particular individual's development during a tutoring program. This case study documents Abby's progress in a variety of learning contexts and across the tutoring sessions. Due to the general involvement of the first author in the LATCH-ON program as well as the tutoring sessions, a certain degree of objectivity may be lost. The first author's perspective may have been influenced by a number of factors. However, in order to prevent such a situation, various data collection methods were used, and the case study was based on these. These are presented as the findings of the first author which may differ from an outsider's experience with the same set of circumstances.

Although the information presented here was collected over a limited time period, nevertheless, the work is encouraging as it provides evidence of reorientation towards the provision of literacy education for students with intellectual disability in young adulthood. Teachers too should be encouraged as it demonstrates that their efforts can be rewarded with progress. A number of issues, such as the role and effectiveness of technology with this group of learners were also raised and these need researcher attention. The case study has provided evidence that there is a need for more research with longer time frames that focus on the processes and strategies that can be used to support 
ongoing development in literacy. Young people with intellectual disability will no doubt benefit from the validation of specific instructional strategies that can facilitate their learning and literacy development.

\section{Correspondence}

Christa van Kraayenoord - Fred and Eleanor Schonell Special Education Research Centre, The University of Queensland, Brisbane, Qld 4072, Australia • Telephone: +61 733656472

- Facsimile: +6I 733658553 - Email:

c.vankraayenoord@mailbox.uq.edu.au

\section{References}

Adams, M.J. (1990). Beginning to Read: Thinking and Learning about Print. Cambridge: Massachusetts Institute of Technology.

Bochner, S., \& Pieterse, M. (1996). Teenagers with Down syndrome in a time of changing policies and practices: Progress of students who were born between 1971 and 1978. International Journal of Disability, Development, and Education, 43, 75-95.

Buckley, S. (1985). Attaining basic educational skills: Reading writing and number. In D. Lane \& B. Stratford (Eds.), Current Approaches to Down Syndrome (pp. 315344). London: Cassell.

Buckley, S., \& Bird, G. (1993). Teaching children with Down's syndrome to read. Down's syndrome: Research and Practice, $1(1), 34-39$.

Conners, F.A. (1992). Reading instruction for students with moderate mental retardation: Review and analysis for research. American Journal on Mental Retardation, 96, 577-597.

Cossu, G., Rossini, F., \& Marshall, J.C. (1993). When reading is acquired but phonemic awareness is not: A study of literacy in Down's syndrome. Cognition, 46, 129-138.

Farrell, M., \& Elkins, J. (1991). Literacy and the adolescent with Down syndrome. In C.J. Denholm (Ed.), Adolescents with Down syndrome: International Perspectives on Research and Programme Development (pp. 15-26). Victoria, BC: University of Victoria.

Fowler, A.E., Doherty, B.J., \& Boynton, L. (1995). The basis of reading skill in young adults with Down syndrome. In L. Nadel \& D. Rosenthal (Eds.), Down Syndrome: Living and Learning in the Community (pp. 182-196). New York: Wiley-Liss.

Jenkinson, J.C. (1992). The use of letter position cues in the visual processing of words by children with an intellectual disability and non-disabled children. International Journal of Disability, Development, and Education, 39, 61-76.

Kabrich, M., \& McCutchen, D. (1996). Phonemic support in comprehension: Comparisons between children with and without mild mental retardation. American Journal on Mental Retardation, 100, 510-527.

Kemp, C. (1996). Does teaching young children with disabilities to read facilitate their language development? A critical review of current theory and empirical evidence. International Journal of Disability, Development, and Education, 43, 175-187.
Koppenhaver, D., Spadorcia, S., \& Harrison, M. (1998, March). Section II: Reading comprehension research for students with low incidence disabilities. In R. Gersten, J. Williams, L. Fuchs, S. Baker, D. Koppenhaver, S. Spadorcia, \& M. Harrison (Eds.), Improving Reading Comprehension for Children with Disabilities: A Review of Research. Draft Final Report. Washington, DC: US Department of Education.

Lalli, J.S., \& Browder, D.M. (1993). Comparison of sight word training procedures with validation of the most practical procedure in teaching reading for daily living. Research in Developmental Disabilities, 14, 107-127.

Marston, D., Deno, S.L., Kim, D., Diment, K., \& Rogers, D. (1995). Comparison of reading intervention approaches for students with mild disabilities. Exceptional Children, $62,20-37$.

Moni, K.B. \& Jobling, A. (2000). LATCH-ON: A program to develop literacy in young adults with Down syndrome. Journal of Adolescent o A Adult Literacy, 44, 40-49.

Neale, M.D. (1989). Neale Analysis of Reading Ability - Revised. Hawthorn, Victoria: Australian Council for Educational Research.

Phonics Alive! [Computer software]. (1996). Sydney: Advanced Software.

Silverman, D. (1993). Interpreting Qualitative Data: Methods for Analysing Talk, Text and Interaction. London: Sage.

Tingey, C. (1988). Cutting the umbilical cord: Parental perspectives. In S. Pueschel (Ed.), The Young Person with Down Syndrome: Transition from Adolescence to Adulthood (pp. 5-22). Baltimore: Paul H. Brookes.

van Kraayenoord, C.E. (1992). A survey of adult literacy provision for people with intellectual disabilities. Brisbane: The University of Queensland, Schonell Special Education Research Centre.

Wolman, C., van den Broek, P., \& Lorch, R.F. (1997). Effects of causal structure on immediate and delayed story recall by children with mild mental retardation, children with learning disabilities, and children without disabilities. The Journal of Special Education, 30, 439455 .

Woodcock, R.W., \& Johnson, M.B. (1989). Woodcock-Johnson Psycho-Educational Battery - Revised. Chicago: Riverside. 